\title{
Intrastromal injection of bevacizumab in patients with corneal neovascularization
}

\author{
Injeção intraestromal de bevacizumabe em pacientes com neovascularização corneana
}

\author{
Ana Carolina Cabreira Vieira ${ }^{1}$, Ana luisa Höfling-Lima ${ }^{1}$, José Álvaro P. Gomes ${ }^{1}$, Denise de Freitas ${ }^{1}$, Michel Eid Farah ${ }^{1}$, Rubens Belfort Jr. ${ }^{1}$
}

\begin{abstract}
Corneal neovascularization (NV) not only reduces visual acuity, but it also causes loss of the cornea's immune privilege, strongly contributing to a worse prognosis in penetrating keratoplasty. Several mediators participate in corneal angiogenesis, and the role of vascular endothelial growth factor (VEGF) has been extensively proven. Anti-VEGF agents have been shown to be effective in slowing the growth of corneal neovessels. Bevacizumab, an anti-VEGF agent, has been successfully used in the treatment of corneal neovascularization. In this paper, we report a series of patients who underwent intracorneal bevacizumab injections to treat corneal vascularization.
\end{abstract}

Keywords: Corneal stroma/drug effects; Corneal neovascularization/drug therapy; Injections, intraocular; Antibodies, monoclonal/administration \& dosage

\section{RESUMO}

Além de causar redução da acuidade visual, a neovascularização corneana leva à perda do privilégio imunológico da córnea, contribuindo paraum pior prognósticoem casos de ceratoplastia penetrante. Diversos mediadores participam da angiogênese corneana. O papel do fator de crescimento endothelial vascular (VEGF) já foi amplamente descrito. Agentes inibidores do VEGF são eficazes na redução do crescimento de neovasos corneanos. Bevacizumabe, um agente anti-VEGF, tem sido utilizado com sucesso no tratamento de neovascularização corneana. Neste artigo, relatamos uma série de pacientes que foram submetidos à injeção intraestromal de bevacizumabe para o tratamento de vascularização corneana.

Descritores: Substância própria/efeito de drogas; Neovascularização da córnea/quimioterapia; Injeções intraoculares; Anticorpos monoclonais/administração \& dosagem

\section{INTRODUCTION}

The cornea maintains its avascularity as a result of a balance between angiogenic and anti-angiogenic factors ${ }^{(1,2)}$. It is believed that under basal conditions, low levels of angiogenic factors and high levels of anti-angiogenic factors maintain the cornea devoid of blood and lymphatic vessels $s^{(3,4)}$. Disruption of this homeostasis may occur in several pathological conditions, including infection, inflammation, ischemia, degeneration and trauma, leading to corneal neovascularization (NV) and consequential loss of corneal transparency ${ }^{(1,2)}$. Corneal NV not only reduces visual acuity, but it also causes loss of the cornea's immune privilege, strongly contributing to a worse prognosis in penetrating keratoplasty ${ }^{(2)}$. Preexisting stromal lymph and blood vessels are strong risk factors for immune rejection after corneal transplantation ${ }^{(5,6)}$.

Several mediators participate in corneal angiogenesis, including basic fibroblast growth factor, transforming growth factor, plateletderived growth factor (PDGF) and vascular endothelial growth factor $(\mathrm{VEGF})^{(2,4,7)}$. The role of VEGF has been extensively proven, and it is often considered the most prominent angiogenic factor ${ }^{(2)}$. VEGF acts in the activation, proliferation, migration and differentiation of vascular endothelial cells. It has been shown that VEGF is up regulated in vascularized human corneas and that endogenous VEGF-A plays a critical role in promoting hemangiogenesis and VEGF-C and VEGF-D in lymphangiogenesis under certain pathological conditions ${ }^{(2,8)}$.

Steroids are the main drugs available for inhibiting angiogene$\mathrm{sis}^{(7)}$. However, their indirect antiangiogenic action is limited, and their use is associated with glaucoma and cataract formation ${ }^{(7)}$.

Anti-VEGF agents have been shown to be effective in slowing the growth of corneal neovessels. Pharmacological neutralization of
VEGF-A completely inhibited both hemangiogenesis and lymphangiogenesis in animal models through primary inhibition of blood and lymphatic vessel formation ${ }^{(8)}$. Bevacizumab (Avastin; Genentech Inc., San Francisco, California, USA) is a humanized version of a monoclonal antibody that binds to all isoforms of VEGF. It has been successfully used in ophthalmology in the treatment of age-related macular degeneration, proliferative diabetic retinopathy and central retinal vein occlusion ${ }^{(9-11)}$

Regarding corneal NV, both topical and subconjunctival administration of bevacizumab were shown to be effective in diminishing vascularization ${ }^{(12,13)}$. However, penetration of the drug through an intact epithelium is considered an issue since its molecular weight is high $(149 \mathrm{kDa})^{(2)}$. For this reason, absorption after topical administration may be limited ${ }^{(2)}$. Subconjunctival injections guarantee better delivery, although local side-effects have been reported ${ }^{(2)}$. Other disadvantages of these methods are the high cost of topic preparations as well as potential systemic side-effects with subconjunctival administration.

Intrastromal corneal injection has been used to treat a case of corneal NV, showing encouraging results ${ }^{(14)}$. A small case series on subconjunctival and intracorneal injections of bevacizumab for the treatment of lipid keratopathy was also recently published ${ }^{(15)}$. The purpose of the present study was to report a series of patients who underwent intracorneal bevacizumab injections to treat corneal vascularization.

\section{METHODS}

Six eyes (of 6 adult patients, 3 male) with corneal NV secondary to various conditions received treatment with intracorneal injection of bevacizumab. 
Ophthalmological examination included BCVA measurement, slit lamp biomicroscopy, applanation tonometry, fundus biomicroscopy and ocular ultrasonography, when fundoscopy was hampered by media opacity.

The injections were performed under a surgical microscope. A $0.1-\mathrm{mL}$ aliquot of bevacizumab $(25 \mathrm{mg} / \mathrm{mL})$ was aseptically prepared in an insulin syringe attached to a 31-gauge needle, and intrastromal injection of approximately $0.01 \mathrm{~mL}(100 \mu \mathrm{g})$ was performed after topical anesthesia. Bevacizumab was injected into the corneal stroma, next to the neovessels (Figure 1). The exact site of injection depended on how far from the limbus or how deep in the cornea the vessels were found. The number of injections in each session depended on the number of quadrants involved. Each case was analyzed individually in order to deliver $0.01 \mathrm{~mL}$ of bevacizumab to every quadrant containing vessels. Bevacizumab was injected at more than one site in the corneal stroma, when more than one quadrant was involved, in order to cover all areas with NV. When central involvement was observed, the needle was introduced in the affected quadrant, adjacent to the vessels, but out of the visual axis.

After the injection, the patients were prescribed topical antibiotics (moxifloxacin) q.i.d. for 5 days.

Patients were seen after the injection and on day 1,7, 15, 21 and 30. After day 30, they were seen in clinic according to their pathology's requirement. Photographs on slit-lamp examination were taken before and at each post-injection follow-up time. Reduction in the extension and caliber of vessels was determined by comparing the initial corneal photograph with the subsequent pictures.

The total area of neovascularization was measured dividing each corneal quadrant into three sections: peripheral (less than $2 \mathrm{~mm}$ from the limbus), midperipheral (2-4 $\mathrm{mm}$ from the limbus) and central (4-6 mm from the limbus). Each corneal quadrant was analyzed and given a score: 0 for no vessels, 1 for peripheral, 3 for midperipheral, and 5 for central neovascularization. The sum of the four quadrants' values determined the global corneal neovascularization score, which was evaluated before and after bevacizumab injection. The clinical aspect of the corneal vessels seen on slit-lamp examination was also considered, and changes in the caliber of neovessels after the procedure were recorded.

Exclusion criteria included pregnancy, uncontrolled systemic hypertension and previous history of myocardial infarction and cerebral vascular accident. This study was approved by the Institutional Review Board of the Federal University of São Paulo, and informed consent was obtained from all patients.

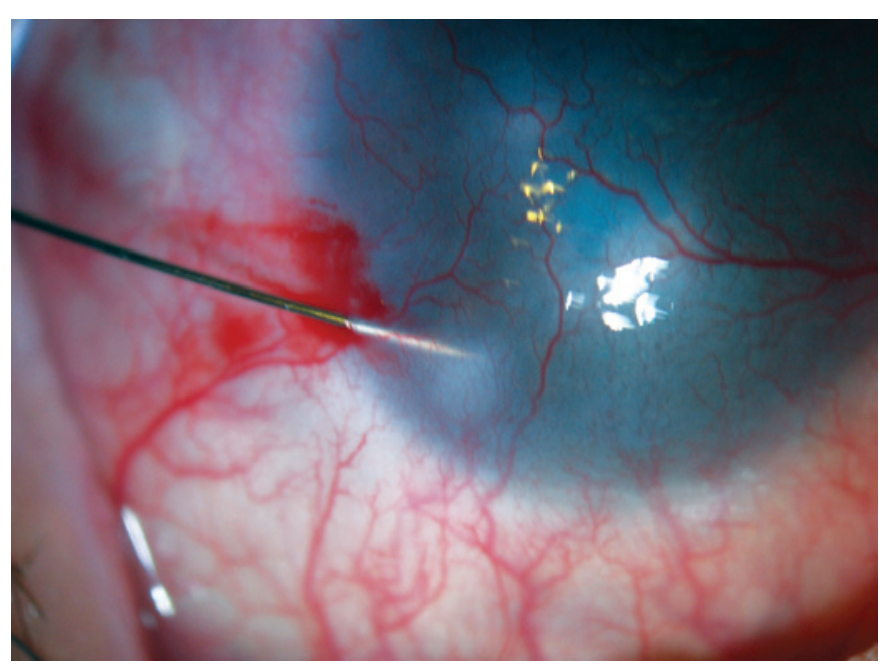

Figure 1. Corneal intrastromal bevacizumab injection.

\section{RESULTS}

The mean age of the 6 patients was 44.67 years ( 18 and 88 years range). The causes of neovascularization included Staphylococcal blepharoconjunctivitis in 1 eye (16.67\%), herpetic stromal keratitis in 2 eyes (33.33\%) and failed keratoplasty in 3 eyes (50.00\%). The characteristics of the patients are found in table 1. The mean followup time was 8.47 months, ranging from 2 to 17 months. The mean number of injections per eye was 1.3, ranging from 1 to 2 .

Topical anesthesia proved sufficient for pain control, with minimal discomfort during the procedure.

Temporary reduction of visual acuity secondary to transitory corneal edema was reported right after the injection and was no longer present on day 1. Intraocular pressure did not change. Intrastromal injection did not cause corneal necrosis, chronic epithelial defect or any other noticeable local or systemic side-effect.

At the screening visit, 2 eyes showed neovessels reaching the central area of the cornea (more than $4 \mathrm{~mm}$ from the limbus), and 4 had peripheral or mid-peripheral involvement ( $2 \mathrm{~mm}$ and $4-6 \mathrm{~mm}$ from the limbus, respectively). In one month, 4 (66.67\%) of the 6 eyes showed a reduction in the total area of neovascularization (patients number 1, 2, 4 and 6), and the caliber of neovessels was decreased in 5 (83.33\%) (patients number 1, 2, 3, 4 and 6) (Figure 2). These results are shown in table 1.

Regarding the number of injections, patients 1,2,4 and 5 received only 1 injection of bevacizumab, while patients 3 and 6 received 2 injections each, with a 30-day interval. Patients 1 and 2 each received injection once and only in 1 quadrant, since both patients presented a single quadrant vascularized and showed visible improvement in vascularization. For the same reason, patient number 4 was injected only once in each one of the 4 quadrants affected. As already mentioned, patient number 6 required two sessions to show diminishment of vascularization. Patient 3 also received 2 injections, however since there was no change in the number of neovessels after the second procedure, we opted not to try another attempt. Due to the absolute lack of response after the first injection, only one attempt was made in patient number 5 . In all other cases, at least a small decrease in the caliber was observed after injection, which encouraged us to believe that there would be a positive response if a second attempt were made. In this case (patient 5), there was absolutely no change in NV after the first injection.

\section{DISCUSSION}

In this study, the injection of bevacizumab into the corneal stroma was performed in order to treat corneal vessels and no local complications were observed in the follow-up period, which ranged from 2 to 17 months. Injection of bevacizumab was not painful. Systemic side effects were also not found.

Comparing to other forms of administration, intrastromal injection may possibly allow greater exposure of the corneal vessels to the drug, as well as delivery of a known concentration of the drug. Topical administration of this drug can be affected by limited penetration through an intact epithelium due to bevacizumab's high molecular weight ${ }^{(2)}$. Intrastromal administration also guarantees less likelihood of treatment failure due to a patient's lack of compliance. Patients may occasionally forget to instill the drug at home, when using a topical preparation.

In this study, three patients with post-keratoplasty corneal neovascularization were treated with intrastromal bevacizumab, 2 patients showing reduction of vessels. In these cases of post-keratoplasty neovascularization reaching the graft, injecting bevacizumab directly into the donor button did not cause corneal necrosis, edema or graft rejection. Inhibition of post-operative hemangiogenesis and lymphangiogenesis, by neutralization of VEGF-A, increases corneal graft survival, even after high-risk transplantation ${ }^{(6)}$. It is possible that 
Table 1. Patients' profiles and outcomes of intracorneal bevacizumab injections

\begin{tabular}{|c|c|c|c|c|c|c|c|}
\hline & Age & Diagnosis & $\begin{array}{l}\text { Site of neovessels } \\
\text { pre-bevacizumab }\end{array}$ & $\begin{array}{c}\text { Score } \\
\text { pre-bevacizumab }\end{array}$ & $\begin{array}{l}\text { Site of neovessels } \\
\text { post-bevacizumab }\end{array}$ & $\begin{array}{c}\text { Score } \\
\text { post-bevacizumab }\end{array}$ & $\begin{array}{l}\text { Reduction of caliber } \\
\text { post-bevacizumab }\end{array}$ \\
\hline 1 & 18 & $\begin{array}{l}\text { Staphylococcal } \\
\text { keratoconjunctivitis }\end{array}$ & $\begin{array}{l}\text { Central } \\
1 \text { quadrant }\end{array}$ & 9 & - & 0 & Yes \\
\hline 2 & 30 & $\begin{array}{l}\text { Post-herpetic } \\
\text { corneal opacity }\end{array}$ & $\begin{array}{l}\text { Midperipheral } \\
1 \text { quadrant }\end{array}$ & 4 & - & 0 & Yes \\
\hline 3 & 88 & $\begin{array}{l}\text { Post-herpetic } \\
\text { corneal opacity }\end{array}$ & $\begin{array}{c}\text { Central } \\
2 \text { quadrants }\end{array}$ & 18 & $\begin{array}{c}\text { Central } \\
2 \text { quadrants }\end{array}$ & 18 & Yes \\
\hline 4 & 20 & Post-keratoplasty & $\begin{array}{l}\text { Peripheral } \\
4 \text { quadrants }\end{array}$ & 4 & $\begin{array}{l}\text { Peripheral } \\
1 \text { quadrant }\end{array}$ & 1 & Yes \\
\hline 5 & 33 & Post-keratoplasty & $\begin{array}{l}\text { Peripheral } \\
4 \text { quadrants }\end{array}$ & 4 & $\begin{array}{l}\text { Peripheral } \\
4 \text { quadrants }\end{array}$ & 4 & No \\
\hline 6 & 79 & Post-keratoplasty & $\begin{array}{l}\text { Peripheral } \\
4 \text { quadrants }\end{array}$ & 4 & $\begin{array}{l}\text { Peripheral } \\
1 \text { quadrant }\end{array}$ & 1 & Yes \\
\hline
\end{tabular}
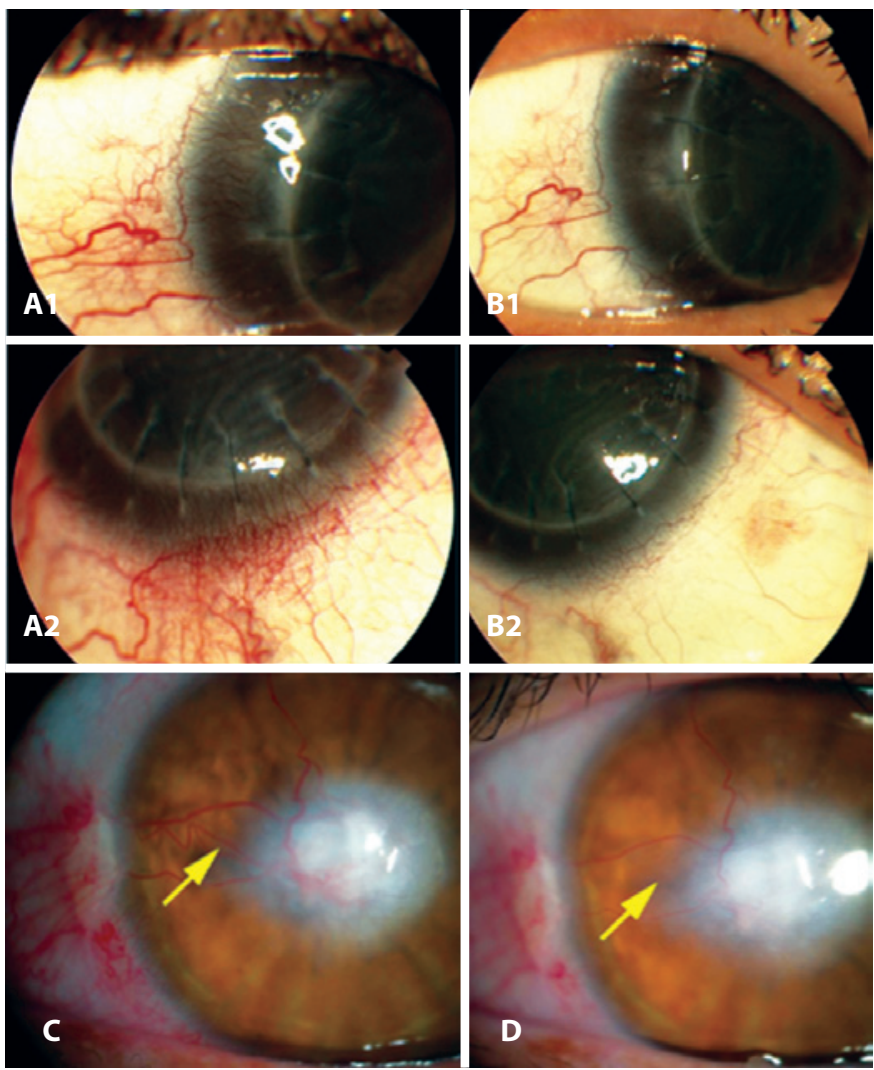

Figure 2. A1-A2) Patient 4: Pre-bevacizumab stromal corneal injection, showing peripheral corneal vessels reaching the graft. B1-B2) Patient 4: Four weeks later, regression of NV. C) Patient 3: Pre-bevacizumab injection. New vessels in the central cornea in two corneal quadrants. D) Patient 3: Three weeks post-injection. Reduction in vessel caliber and number.

other cytokines may have contributed to these results, such as matrix metalloproteinases for example, which may be present in the cornea after transplantation and have angiogenic and anti-angiogenic actions under different conditions ${ }^{(2)}$.

The scoring system used in this paper has not been used in previous studies. Despite not having the ideal scoring system for quantification of corneal neovascularization and documentation of changes in vessels' caliber, our results showed that intracorneal injec- tion of bevacizumab was safe and effective when used for therapy of corneal neovascularization in 6 patients.

Our results suggest that corneal intrastromal injection of bevacizumab may be an additional useful option for management of corneal vascularization. However, our study has limitations: it was an uncontrolled small case series with a short follow-up. The safety of intracorneal bevacizumab injections should be further investigated in a controlled way and with a larger population. Also, the most efficacious administration route has yet to be determined through larger trials.

\section{REFERENCES}

1. Chang JH, Gabison EE, Kato T, Azar DT. Corneal neovascularization. Curr Opin Ophthalmol. 2001;12(4):242-9.

2. Maddula S, Davis DK, Maddula S, Burrow MK, Ambati BK. Horizons in therapy for corneal angiogenesis. Ophthalmology. 2011;118(3):591-9.

3. Hosseini $H$, Nejabat M. A potential therapeutic strategy for inhibition of corneal neovascularization with new anti-VEGF agents. Med Hypotheses. 2007;68(4)799-801.

4. Kvanta A. Ocular angiognesis: the role of growth factors. Acta Ophthalmol Scand. 2006:84(3):282-8

5. Cursiefen C, Maruyama K, Jackson DG, Streilein JW, Kruse FE. Time course of angiogenesis and lymphangiogenesis after brief corneal inflammation. Cornea. 2006; 25(4):443- 7 .

6. Bachmann B, Bock F, Wiegand SJ, Maruyama K, Dana MR, Kruse FE, et al. Promotion of graft survival by vascular endothelial growth factor a neutralization after high-risk corneal transplantation. Arch Ophthalmol. 2008;126(1):71-7.

7. Riazi-Esfahani M, Peyman GA, Aydin E, Kazi AA, Kivilcim M, Sanders D. Prevention of Corneal Neovascularization. Evaluation of Various Commercially Available Compounds in an Experimental Rat Model. Cornea. 2006;25(7):801-5.

8. Cursiefen C, Chen L, Borges LP, Jackson D, Cao J, Radziejewski C, et al. VEGF-A stimulates lymphangiogenesis and hemangiogenesis in inflammatory neovascularization via macrophage recruitment. J Clin Invest 2004;113(7):1040-50.

9. Avery RL, Pieramici DJ, Rabena MD, Castellarin AA, Nasir MA, Giust MJ. Intravitreal bevacizumab (Avastin) for neovascular age-related macular degeneration. Ophthalmology. 2006;113(3):363-372.e5.

10. Avery RL, Pearlman J, Pieramici DJ, Rabena MD, Castellarin AA, Nasir MA, et al. Intravitreal bevacizumab (Avastin) in the treatment of proliferative diabetic retinopathy. Ophthalmology. 2006;113(10):1695.e1-15

11. Pai SA, Shetty R, Vijayan P, Venkatasubramaniam G, Yadav NK, Shetty BK et al. Clinical, anatomic, and electrophysiologic evaluation following intravitreal bevacizumab for macular edema in retinal vein occlusion. Am J Ophthalmol. 2007;143(4):601-6.

12. Dastjerdi MH, Al-Arfaj KM, Nallasamy N, Hamrah P, Jurkunas UV, Pineda R $2^{\text {nd }}$, et al. Topical bevacizumab in the treatment of corneal neovascularization: Results of a prospective, open-label, noncomparative study. Arch Ophthalmol. 2009;127(4):381-9.

13. Bahar I, Kaiserman I, McAllum P, Rootman D, Slomovic A. Subconjunctival bevacizumab injection for corneal neovascularization. Cornea. 2008;27(2):142-147.

14. Hashemian MN, Zare MA, Rahimi F, Mohammadpour M. Deep intrastromal bevacizumab injection for management of corneal stromal vascularization after deep anterior lamellar keratoplasty, a novel technique. Cornea. 2011;30(2):215-8.

15. Oh JY, Kim MK, Wee WR. Subconjunctival and intracorneal bevacizumab injection for corneal neovascularization in lipid keratopathy. Cornea. 2009;28(9):1070-3. 